\title{
A crítica dos argumentos filosóficos a favor da existência de Deus e sua superação na filosofia da religião de Paul Tillich
}

\author{
The criticism of the philosophical arguments in favor of the existence of God \\ and their overcoming in the philosophy of religion of Paul Tillich
}

\author{
Etienne Higuet \\ Doctor en Teología \\ Universidade Federal de Juiz de Fora \\ etienne.higuet@gmail.com \\ Fecha recepción: 25/07/2019 \\ Fecha aceptación: 11/11/2019
}

Como citar este artículo: E. HIGUET. "A crítica dos argumentos filosóficos a favor da existência de Deus e sua superação na filosofia da religião de Paul Tillich" en Palabra y Razón. Revista de Teología, Filosofia y Ciencias de la Religión Nº16, Diciembre 2019, pp. 23-43 https://doi.org/10.29035/pyr.16.23

Resumo: Pretendo apresentar e discutir, neste breve ensaio, a crítica de Paul Tillich aos argumentos filosóficos (ou "provas") tradicionais a favor da existência de Deus ${ }^{1}$. Pesquisarei primeiro as raízes kantianas da crítica, da qual Tillich retoma a terminologia. Em seguida, apresentarei a visão de Tillich, que incluirá uma crítica da posição kantiana e avanços conseguidos por Tillich em relação a Kant, na perspectiva de uma ontologia existencial e de uma razão ontológica. Nas considerações finais, mostrarei brevemente como a reflexão de Kant condiciona tanto a visão de Tillich quanto a posição de filósofos "pós-modernos" como Jacques Derrida e Jean-Luc Nancy.

Palavras-chave: existência de Deus; argumentos; Kant; Tillich; interpretação existencial; pósmodernidade.

Abstract: I intend to present and discuss, in this short essay, the criticism of Paul Tillich to the tradicional philosophical arguments (or "evidences") in favour of the existence of God. I will search first the kantian roots of this criticism, which Tillich resumes terminology. Then I will present the vision of Tillich, that will include a critique of Kantian position and advances achieved by Tillich in relation to Kant, from the perspective of an existential ontology and an ontological reason. In closing remarks, I will show briefly how the reflection of Kant conditions both the vision of Tillich as the position of "post-modern" philosophers such as Jacques Derrida and Jean-Luc Nancy.

Keywords: existence of God; arguments; Kant; Tillich; existential interpretation; postmodernity.

\footnotetext{
${ }^{1}$ Os principais expoentes dos argumentos são Anselmo de Cantuária, com o seu "argumento ontológico", inspirado em Agostinho e retomado mais tarde por Descartes, e Tomás de Aquino, com as suas "cinco vias" (quinque viae). Não é possível apresentar aqui a formulação original dos argumentos, que aparecerá subjacente à exposição dos pensamentos de Kant e Tillich. Sobre a elaboração medieval dos argumentos, remeto a E. GILSON e P. BOEHNER. História da Filosofia Cristã: desde as origens até Nicolau de Cusa, 13ª . ed., Petrópolis: Vozes, 2012. Há uma exposição quase exaustiva da história dos argumentos na tese de G. E. EMÍLIO. Os argumentos da existência de Deus à luz da ontologia de Paul Tillich. Universidade Federal de São Paulo, Escola de Filosofia, Letras e Ciências Humanas: Guarulhos - SP, Brasil, 2017. Acessível no site da Universidade.
} 


\section{Introdução}

Num artigo publicado em 2014, estudei a contribuição de Paul Tillich à superação do teísmo e da ontoteologia. Para Tillich, o Deus do teísmo teológico é um ser ao lado dos outros, isto é, uma parte do conjunto da realidade, submetida à estrutura do real, por mais que seja a parte mais importante do real. Ele é um ser, não o ser-em-si. Submetido à estrutura sujeito-objeto, ele se torna objeto para nós sujeitos e, enquanto sujeito, faz de nós seus objetos. Deus aparece como o tirano invencível que poda a nossa subjetividade e a nossa liberdade. Já mostrei também que, para Tillich, a superação do teísmo exigia uma reinterpretação das chamadas "provas da existência de Deus". Pretendo retomar agora e desenvolver a questão dos argumentos filosóficos a favor da existência de Deus, mostrando como esse problema preocupou Tillich durante boa parte da sua carreira, especialmente na sua sistematização teológica, já na Dogmática de 1925 e, sobretudo, na Teologia Sistemática (de 1951 em diante), em alguns textos conexos e em diversos cursos oferecidos na Alemanha e nos Estados Unidos.

Objetivo, em primeiro lugar, explicitar a inspiração kantiana de Tillich, sempre reconhecida por ele. $\mathrm{O}$ que não o impediu de mostrar que o seu ilustre antecessor ficara a meio caminho, quando não submeteu o argumento moral à crítica proferida contra os argumentos ontológico, cosmológico e teleológico. Para Kant, a existência de Deus não pode constituir o objeto de um conhecimento seguro e certo na ótica da filosofia transcendental, pois assim concebido Deus seria um transcendente ou uma "coisa-em-si" que ultrapassa as condições de possibilidade do nosso conhecimento objetivo. As categorias do entendimento não são aplicáveis a um objeto transcendente, inclusive Deus, pois, neste caso, nenhuma intuição sensível corresponde às formas do entendimento que são as categorias. Não se pode inferir a existência de Deus a partir do seu conceito. Mas Kant acabou optando pela prova moral da existência de Deus, ao considerar a existência de Deus como um postulado da razão prática. $\mathrm{O}$ argumento de Kant, baseado na necessidade da razão prática, conduz a um conhecimento de Deus, mas só numa relação prática. Não há demonstração da existência de Deus nem da sua não-existência, mas Deus é a condição (transcendental) de possibilidade da moral e da felicidade. A reflexão de Kant desemboca numa espécie de "fé da razão".

Já na Dogmática de 1925, Tillich mostra os limites da argumentação kantiana. É que as provas de Deus não são provas, mas, antes, racionalizações e formas de expressão da condição de criatura. Elas manifestam um abalo do condicionado na sua mundaneidade, sendo objeto de uma intuição originária vinculada a uma atitude místico-transcendente. 
Para Tillich, Deus não "existe", mas é o ser-em-si para além da essência e da existência. Resulta daí que todo argumento a favor da existência de Deus seria uma negação de Deus. Na realidade, os argumentos ou provas da existência de Deus são expressões da pergunta por Deus que está implícita na finitude humana. O chamado argumento ontológico aponta para a estrutura ontológica da finitude. Os chamados argumentos cosmológico e teleológico são a forma tradicional da questão do ser que vence o não ser e da coragem que supera a angústia.

Não há uma demonstração lógica da existência de Deus, mas uma consciência ontológica e um conhecimento cosmológico do incondicional. É o ser humano inteiro, em todas as suas funções, que tem consciência do incondicionado. Este não é um ser, nem o mais alto, nem mesmo Deus. Ao termo Deus correspondem diversos símbolos concretos que expressam a nossa preocupação suprema ou o fato de sermos tocados por algo incondicional. "Mas esse 'algo' não é uma coisa, mas o poder de ser no qual todos os seres participam".

A validade dos argumentos reside na descrição, negativa ou positiva, da situação humana, que eles fornecem, na descrição da finitude do ser humano e do seu mundo e, ao mesmo tempo, na descrição da participação do Infinito no finito e vice-versa. O que não se justifica é o salto que eles fazem, da análise da finitude da existência para um ser chamado Deus. A descrição da realidade encontrada como contingente e condicionada numa corrente de causas e efeitos é um elemento existencial na filosofia do passado e do presente. É o que os filósofos da existência chamam descrição da finitude.

Haverá sem dúvida, na concepção tillichiana da fé como o "estar tomado por aquilo que nos toca incondicionalmente", um substituto para os argumentos lógicos a favor da existência de Deus. Aliás, aqui reencontramos Kant, que escreveu no prefácio à segunda edição da Crítica da Razão pura: "Tive, portanto, de suprimir o saber para obter lugar para a fé" 2 . Na Crítica da Razão prática, o incondicionado se manifesta na liberdade e na lei moral. Em Tillich, o incondicionado se manifesta na religião. Tillich compartilha com Kant e com alguns filósofos da linha chamada pósmoderna e pós-heideggeriana uma concepção consequente da "fé da razão".

\footnotetext{
${ }^{2}$ W. WEISCHEDEL (Hrsg.). I. KANT, Werke in zehn Bänden. Band 3, Kritik der reinen Vernunft. Erster Teil Darmstadt : Wissenschaftliche Buchgesellschaft, Sonderausgabe, 1983, p. 33: Ich musste also das Wissen aufheben, um zum Glauben Platz zu bekommen.
} 


\section{Immanuel Kant: A desmontagem das provas especulativas da existência de Deus e a elaboração da prova moral na Crítica da razão pura ${ }^{3}$}

A existência de Deus não pode constituir o objeto de um conhecimento seguro e certo na ótica da filosofia transcendental, pois assim concebido Deus seria um transcendente ou uma "coisa-em-si" que ultrapassa as condições de possibilidade do nosso conhecimento objetivo. Na "Analítica dos princípios", o conhecimento se reduz a relacionar à unidade sintética da apercepção - constituída a partir das categorias (substância, causalidade, realidade, existência) - uma dada intuição, que será sempre uma intuição sensível, não intelectual, subordinada às formas subjetivas e a priori do espaço e do tempo. As categorias do entendimento não são aplicáveis a um objeto transcendente, inclusive Deus.

Mas a "dialética transcendental" mostra que a persistência transcendental das questões metafísicas últimas da razão torna urgente uma auto-reflexão crítica do poder de conhecer a priori: "O entendimento não pode fazer mais do que antecipar a forma de uma experiência possível em geral [...] não pode jamais ultrapassar os limites da sensibilidade, no interior dos quais somente nos são dados objetos" Contudo, as questões especiais da metafísica sobre a alma, o mundo e Deus não são vãs, pois fazem parte da estrutura mesma dos raciocínios da razão e são o sintoma de uma metafísica natural no homem. A interrogação metafísica é uma necessidade da razão humana. Para a razão humana, colocar estas questões é uma necessidade lógico-subjetiva, mas a razão é levada à ilusão transcendental de acreditar que suas máximas lógico-subjetivas correspondem a realidades, já que, neste caso, nenhuma intuição sensível corresponde às formas do entendimento que são as categorias 5 .

Herdeiro de uma longa tradição marcada pelo cristianismo, Kant coloca a questão de Deus como problema de um princípio transcendente e personificado de tudo o que é, o ens realissimum, o ente mais real de todos, que contém em si a possibilidade de todos os entes finitos.

A partir dessa estrutura de raciocínio decorrerão as provas da existência de Deus, que Kant crê poder reduzir, de maneira exaustiva, a três argumentos fundamentais: físico-teológico, cosmológico e ontológico. Kant mostrará que as duas primeiras provas são retomadas inconscientes da prova ontológica, mas que esta é inadmissível de um ponto de vista crítico. Trata-se de uma prova estritamente

\footnotetext{
${ }^{3}$ A expressão e parte da exposição a seguir remetem a L. LANGLOIS. O fim das coisas e o fim da liberdade: a ideia de Deus na Crítica da razão pura, In L. LANGLOIS \& Y. C. ZARKA (orgs.) Os filósofos e a questão de Deus. Loyola: São Paulo, 2009, pp. 199-220.

${ }^{4}$ Crítica da razão pura. Trad. A. RENAUT, Gallimard: Paris, 2001, p. 300, A 246-247 / B 303.

${ }^{5}$ L. LANGLOIS. O fim das coisas e o fim da liberdade, pp. 202-206.
} 
a priori, deduzindo diretamente (analiticamente) do conceito de Deus ou do ser perfeitíssimo - da sua possibilidade lógica - a necessidade de sua existência. Em relação a ela, Kant concluirá que, do conceito de perfeição à existência, ou da existência ao conceito de perfeição, o vínculo é finalmente analítico. As ordens do lógico e do real correspondem-se numa unidade puramente analítica.

\section{Leibniz,}

Segundo a tradição (Agostinho, Anselmo, Descartes) ainda reavivada por

Deus é o único ser cuja existência pode ser considerada consequência necessária de seu conteúdo nocional. Uma vez que, por definição, ele é um ser perfeito, acima do qual nada se encontra, a existência deve ser um de seus atributos necessários, pois se Deus não existisse seria ainda mais imperfeito do que o menor dos existentes contingentes (tudo o que existe efetivamente sendo superior na ordem do ser a tudo o que é simplesmente possível), o que manifestamente se opõe ao seu conceito ${ }^{6}$.

Ora, é impossível "erigir a existência ao nível de um predicado real" sem que o sujeito da predicação tenha sido dado na experiência sensível. O sujeito precisa primeiro ser dado para que as suas propriedades essenciais possam the ser aplicadas. Ora, isso é impossível no caso de Deus, porque dele não há conteúdo sensível, já que está além da experiência. Cede-se aqui a uma ilusão transcendental.

A prova cosmológica depende do mesmo pressuposto (inferir a existência de Deus a partir do seu conceito), mas parte do problema da existência em geral. Ela não é totalmente a priori, mas infere da contingência de todos os seres conhecidos e reais a existência de um ser ou substância necessário como causa, posto fora da série de acontecimentos do mundo, e que é o único a explicar sua possibilidade. "Mas o conceito de tal ser necessário leva uma vez mais a absorver a existência na lógica, em outros termos, a deduzir a priori um existente, o que é injustificável do ponto de vista crítico". ${ }^{8}$ De novo, a dedução é ilegítima, pois o princípio de conexão causal só tem validade e sentido no mundo dos fenômenos, ou seja, no mundo da experiência empírica. Há um salto indevido do empírico para o ontológico. Não há como provar a existência de um ser necessário, nem que esse ser seja o ser perfeitíssimo e realíssimo ou Deus.

A prova físico-teológica (ou teleológica), que se apoia na observação das características do mundo sensível, parece livre da confusão entre possibilidade lógica e possibilidade transcendental com base empírica. É que a finalidade (ou teleologia)

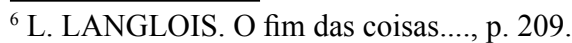

${ }^{7}$ I. KANT. Crítica da razão pura, p. 300, A 246-247 / B 303.

${ }^{8}$ L. LANGLOIS. O fim das coisas..., p. 211.
} 
experimentada na percepção da ordem da natureza empírica no seu conjunto parece remeter ao conceito de uma causa intencional que opera segundo Ideias ou por liberdade, isto é, de modo diferente da causalidade própria aos fenômenos, a única acessível à linguagem da natureza físico-matemática. Contudo,

Resta que a síntese entre a causa final e a determinação concreta dos fenômenos que subjazem a essa prova é em si irrealizável. Apontando para um existente concebido como a condição necessária das existências finalizadas, esse argumento traz a marca da prova cosmológica, concluindo do contingente para o necessário, e mais originalmente ainda da prova ontológica, concluindo do conceito para a existência ${ }^{9}$.

O uso regulador das Ideias da razão pura permite, todavia, a emissão da "hipótese de um ordenamento global da natureza empírica, como se esta fosse o efeito de uma intenção inteligente" ${ }^{10}$.

Na Crítica da razão pura, a questão da finalidade acaba se deslocando do campo da teoria para o campo da prática. Ao introduzir uma finalidade na natureza, a razão é forçada a admitir que existe outra causalidade além do determinismo natural, que só pode ser pensada por nós em analogia com os produtos da arte humana. Para realizar a unidade da experiência na apreensão do Bem total, precisamos recorrer ao uso prático da razão, que se ocupa com uma outra legislação, que concerne não mais diretamente à natureza mas à determinação imediata da vontade livre. A liberdade se impõe a nosso consentimento (à nossa consciência moral) como uma evidência prática, supondo a capacidade de agir segundo um princípio puramente racional da vontade, buscando na razão prática sua única lei. As leis práticas puras, isto é, as leis morais, cujo fim declarado é fornecido completamente a priori pela razão, apresentam-se como produtos da razão pura ${ }^{11}$.

Em outras palavras, Kant encontra, no conjunto de princípios que constituem a consciência moral - a consciência de dever agir conforme a lei moral - a base para apreender os objetos metafísicos. Assim, as questões que preocupam sumamente a razão comum: a liberdade, a existência de Deus, a esperança numa vida futura, que tendem a se confundir no uso especulativo, se subordinam, no uso prático, à sua verdadeira condição de inteligibilidade: a saber, o princípio inerente à vontade finita que comanda imediatamente suas ações numa lei de liberdade. Somente o princípio da dignidade do homem como ser livre permite unir numa perspectiva única e globalmente significativa a ideia de Deus e a do mundo.

\footnotetext{
${ }^{9}$ L. LANGLOIS. O fim das coisas..., p. 212.

${ }^{10}$ L. LANGLOIS. O fim das coisas..., p. 213.

${ }^{11}$ cf. Crítica da razão pura, p. 655 / A 800/ B 828.
} 
Por outro lado, não há, em nosso mundo sensível, correspondência perfeita entre o bem e a felicidade, entre a qualidade moral e ordem dos efeitos, à qual a lei moral nos daria direito. Esse vínculo precisa ser projetado em um mundo inteligível, do qual a nossa liberdade não é a condição. "O sentido de nossa aventura como seres finitos supõe um princípio de ligação necessário entre os elementos do soberano Bem que a natureza, ou nossa natureza, não contém em si. Esse princípio só pode ser Deus" ". Como, no mundo fenomênico, os valores morais (justiça, bondade etc.) não estão realizados, é necessário que além deste mundo haja um mundo metafísico no qual o que é seja idêntico com o que deve ser. Este postulado requer uma unidade sintética superior entre esse ser e o dever ser. A essa síntese unitária Kant chama Deus. "A Ideia de Deus assegura que não existe abismo entre as leis da natureza e da liberdade, mas uma continuidade baseada em um soberano Bem originário" ${ }^{13}$. Por outro lado, se o mundo inteligível não está sujeito às formas do espaço e do tempo nem das categorias, a vontade pura justifica a crença na imortalidade da alma.

Assim, Kant acabou optando pela prova moral da existência de Deus. Estuda a existência de Deus como um postulado da razão prática. O suporte, para esta prova, está no bem supremo, que reúne em si moralidade e felicidade e que constitui o objeto adequado da lei moral. O argumento de Kant, baseado na necessidade da razão prática, conduz a um conhecimento de Deus, mas só numa relação prática. Não há demonstração da existência de Deus nem da sua não-existência, mas Deus é, para Kant, a condição (transcendental) de possibilidade da moral e da felicidade ${ }^{14}$.

Em ligação com o famoso trecho do prefácio à segunda edição da Crítica da razão pura: "Tive, portanto, de suprimir o saber para obter lugar para a fé", estaríamos aqui na frente de uma forma de fé da razão? É a opinião de muitos comentaristas, entre outros Wilhelm Weischedel: "O fundamento moral (da filosofia teológica de Kant) faz com que o conceito de Deus possua o caráter de um postulado e que a certeza que o acompanha se apresente como fé filosófica" ${ }^{15}$. Kant descreve o postulado da existência de Deus como uma hipótese subjetiva, que possui "uma necessidade racional subjetiva, porém verdadeira e incondicionada" ${ }^{16}$. É um fundamento subjetivo do saber, que é, contudo, válido para uma razão prática. Assim, a subjetividade não é puro arbitrário do indivíduo, mas constitui uma necessidade, vinculada à essência do ser humano como sujeito moral, de admitir a existência de

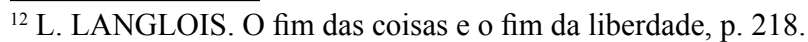

${ }^{13}$ L. LANGLOIS. O fim das coisas..., p. 218.

${ }^{14} \mathrm{Cf}$. L. LANGLOIS, O fim das coisas e o fim da liberdade, pp. 206-220.

${ }^{15}$ W. WEISCHEDEL. Der Gott der Philosophen. München: Nymphenburger Verlagshandlung, vol. 1, $3^{\text {a }}$. Ed., 1975, p. 211.

${ }^{16}$ Weischedel cita Kant a partir das obras em seis volumes editadas pelo próprio Weischedel : W. WEISCHEDEL (hrsg.). I. KANT. Werke in sechs Bänden, Frankfurt/Darmstadt, 1957ss. Aqui, vol. IV, p. 117.
} 
Deus. Kant descreve também a convicção da existência de Deus como "pura fé da razão", já que a razão pura é a fonte de onde ela jorra. Afinal, para Kant, a metafísica é mais uma questão de fé que de saber. $\mathrm{O}$ fato de que suas afirmações sejam teoricamente insuficientes - como as afirmações de toda fé - não tira nada da sua validade, pois essa fé está plenamente assegurada por um pressuposto praticamente bem fundamentado, teoricamente irrefutáve $1^{17}$. Em consequência, toda fé revelada pressupõe a fé da razão.

\section{A visão de Paul Tillich (1886-1965)}

\subsection{A dogmática de $1925^{18}$}

Na dogmática de 1925, Paul Tillich trata das provas da existência de Deus na seção: $O$ ente enquanto conforme à essência na revelação perfeita (de Deus e do mundo na sua união). A primeira parte trata do ente na sua pura condição de criatura. As teses 26 a 29 dizem respeito aos limites do criado. Vejamos a tese 26: "Na irrupção da revelação, cada ente experimenta o abalo (Erschütterung) do seu ser-si-mesmo ou da sua mundaneidade, e da reorientação para o ser que o (= o si mesmo) sustenta"19. O nosso tema vem na tese 29: "As provas da existência de Deus são uma expressão racional, logo inadequada, da condição de criatura do ente. É mais apropriado ver nelas testemunhos do abalo e da reorientação que afetam o conhecimento do mundo"20.

Tillich observa primeiro que as provas de Deus são estudadas no tratado da criatura, não no tratado de Deus (estamos numa perspectiva teológica). É que elas não são provas da existência de Deus, mas, antes, formas de expressão da condição de criatura. Negativamente, elas são racionalizações, positivamente, elas são formas de expressão. Isso se vê especialmente na prova cosmológica: ela parte do condicionado enquanto tal para elevar-se até o incondicionado. Pode-se proceder a partir dos fatos (de uma série causal até uma causa incondicionada) ou a partir dos conceitos (da contingência de cada ente para o pensamento até a conclusão de um ente necessário, do qual o pensamento não pode escapar). Nas duas deduções, parte-se do existente em geral para inferir um existente incondicionalmente: se algo existe, então algo deve existir incondicionalmente. Esta fórmula exprime o abalo do condicionado na sua mundaneidade. Logo, é uma intuição originária, não uma

\footnotetext{
${ }^{17}$ I. KANT. Werke in sechs Bänden, vol. III, p. 287. W. WEISCHEDEL,Der Gott der Philosophen, p. 210.

${ }^{18}$ Estou usando a tradução francesa : P. TILLICH. Dogmatique. Cours donné à Marbourg en 1925. Cerf/Labor et Fides/Laval: Paris/Genève/Québec, 1997.

${ }^{19}$ P. TILLICH. Dogmatique, p. 121.

${ }^{20}$ P. TILLICH. Dogmatique, p. 132.
} 
prova $^{21}$. Pois, pressupõe-se o que seria preciso provar: o ente é algo condicionado e, em consequência, remete imediatamente ao incondicionado. Se o incondicionado for o que é preciso provar, inferindo a partir do condicionado, a prova será insuficiente. Isso foi bem visto por Kant. Contudo, a forma do argumento pode se manter intata enquanto expressão do abalo.

Tillich dá razão a Kant por reduzir a prova teleológica à prova cosmológica: é que o princípio da causa final já inclui o princípio de causalidade. Contudo, mesmo se a prova cai, continua possível pensar uma finalidade inerente ao mundo ou teleologia, na medida em que a prova só leva até a ideia do cosmos. Mas o cosmos real está atravessado por uma "dis-teleologia" tão poderosa quanto a sua teleologia. Kant ficou impressionado pela prova teleológica de Deus. Na realidade, a prova não leva até Deus, mas até o sentido do ente. Tendo sentido, o ente fica preservado do abalo, mesmo entrando constantemente em confronto com o não-sentido. Porém, todo ato de sentido, como cada ente, está exposto à relação, aberta pelo choque revelatório, ao fundamento incondicionado do sentido, assim como ao abismo incondicionado, de modo que um sentido individual nunca pode se sustentar a si mesmo. De qualquer modo, fica claro que, seja a respeito do ser ou do sentido, é sempre o abalo e a reviravolta que encontram expressão nas provas de Deus. Essa concepção da prova teleológica exprime também o que há de justo na prova moral de Deus. Não é a harmonia da virtude e da beatitude, como em Kant, mas a incondicionalidade do sentido no agir prático.

A tentativa mais acabada de racionalização é a prova ontológica de Deus. Isto é: a ideia do ser mais perfeito inclui a sua existência, já que o ser mais perfeito é maior que quando é apenas pensado. Fundamenta-se na ideia que o ser é uma perfeição. A crítica kantiana fracassa, porque o ser é mesmo um predicado (contrariamente ao que diz Kant); mas é um predicado que não afeta a essência e o valor de uma coisa em si mesma. O que precisamos fazer é perguntar qual é o sentido de designar o ser como uma perfeição. Para o pressuposto realista, ser perfeito é possuir o grau mais elevado

\footnotetext{
${ }^{21}$ Em Perspectivas da teologia protestante dos séculos XIX X XX, Tillich traz uma observação interessante a respeito da intuição: "Opõe-se hoje a razão à intuição, mas é um erro, pois a razão intuitiva é uma razão não analítica que se expressa em termos de descrição. A razão intuitiva procura compreender o sentido dos objetos, sejam eles psíquicos ou físicos, e não analisa-los; ela nos permite, graças ao seu método descritivo, compreender as estruturas da vida e do espírito. Cada vez que procuramos descobrir significados [...] estamos no campo da razão intuitiva, como estava Platão nos seus diálogos [...]. Ao querer saber o que é a virtude, a coragem, a força de alma, escolhemos certo número de exemplos, nos deixando guiar pelo sentido comum das palavras. Depois os comparamos a fim de descobrir o conceito universal que se aplica aos diferentes exemplos e exprime o que eles têm de idêntico. Este método, chamado hoje método fenomenológico, é indispensável no estudo da literatura, da teologia ou da filosofia. Em filosofia, ele foi atualizado por Edmund Husserl (1859-1938), mas não inventado, nas suas Investigações lógicas, por volta de 1900. Ele foi um precursor dos existencialistas." Uso a tradução francesa: P. TILLICH. La naissance de l'esprit moderne et la théologie protestante. Cerf: Paris, 1972, p. 43.
} 
ou a plenitude do ser. Além disso, o ente mais perfeito, que possui a plenitude toda de ser, deve ser não um simples objeto de pensamento, mas também uma realidade, algo objetivo. Essa afirmação não é o resultado de um silogismo, mas de uma atitude: o ser mais perfeito, não podemos não pensa-lo. Pois pensar e ser constituem uma unidade. Os graus de generalidade, logo do pensamento, já são os graus do ser. Este conceito de ser difere profundamente do conceito de Kant: é um conceito místicotranscendente. Então, é correto dizer: o sendo (Seiende) incondicionalmente não pode ser apenas pensado. Senão, não seria o sendo incondicionalmente. Ele constitui o prius do pensamento, não o inverso.

Precisamos colocar esse modo de pensar no contexto de acesso místico imediato ao sendo incondicionalmente, característico do pensamento medieval, e de confiança racional no mundo, que ainda existia na época da Aufklärung. A prova ontológica é apenas um caminhar intelectual a partir dos mais baixos graus do ser até o mais alto. Ela não é um abalo religioso. O incondicionado, que é o prius do pensamento, não pode ser simplesmente objeto do pensamento, mas se aniquila enquanto objeto. O ser incondicionado é o abismo e o fundamento do pensamento. As provas cosmológica e noológica (= oriunda do espírito ou pensamento: Nous) exprimem a nossa sujeição ao abalo e à reorientação da mundaneidade. Elas exprimem o fato de que o nosso conhecimento do mundo não é um refúgio onde se poderia escapar de Deus: elas mostram, antes, que o abalo que vem de Deus atinge também o pensamento. É apenas sobre esta base que a filosofia da religião se torna possível.

\subsection{Teísmo e supranaturalismo}

No Tillich do período americano, a crítica do teísmo acompanha a crítica do supranaturalismo. O supranaturalismo é uma teologia que afirma a existência de um mundo supranatural ao lado ou acima do mundo natural, um mundo no qual o incondicionado ocupa um determinado espaço - ou seja, Deus torna-se um objeto mundano, a criação um ato no começo do tempo e a realização definitiva uma situação futura das coisas. Isto é, o incondicionado é transformado em condicionado.

O supranaturalismo separa Deus como um ser, o ser supremo, dos demais seres, ao lado e acima dos quais ele tem a sua existência. Este Deus criou o universo num determinado momento do tempo, dirige-o a um fim, interfere em seus processos normais para superar a resistência e cumprir seu propósito, e o conduzirá à consumação numa catástrofe final. Esta interpretação transforma a infinitude de Deus em finitude dependente das categorias de espaço, tempo, causalidade e substância. 
Para Tilich, Deus não seria Deus se não fosse o fundamento criativo de tudo o que tem ser. De fato, ele é o poder infinito e incondicional do ser ou, utilizando uma abstração ainda mais radical, ele é o ser-em-si. Neste sentido, Deus não está ao lado das coisas nem "acima" delas, mas está mais próximo das coisas do que elas de si mesmas. Ele é o seu fundamento criativo, aqui e agora, sempre e em todo lugar. A afirmação fundamental sobre Deus, que ele é o ser-em-si ou o poder do ser, exclui que ele seja um ente ao lado de outros entes, uma coisa cósmica ao lado de outras, e não o fundamento ou o sentido do ser.

Assim, o Deus do teísmo teológico é um ser ao lado dos outros, isto é, uma parte do conjunto da realidade, submetida à estrutura do real, por mais que seja a parte mais importante do real. Ele é um ser, não o ser-em-si. Submetido à estrutura sujeito-objeto, ele se torna objeto para nós sujeitos e, enquanto sujeito, faz de nós seus objetos. Deus aparece como o tirano invencível que poda a nossa subjetividade e a nossa liberdade.

Além de desenvolver os pretensos argumentos a favor da existência de Deus, o teísmo teológico procura sistematizar teoricamente o encontro pessoal com Deus como encontro de duas pessoas que possuem uma realidade independente uma da outra. É a crítica do teísmo e do supranaturalismo que exige uma reinterpretação das chamadas "provas da existência de Deus", isto é, implica na rejeição das provas da existência de Deus enquanto "provas"22.

\subsection{Os argumentos na Teologia Sistemática e no artigo Dois tipos de filosofia da religião}

Na Teologia Sistemática, Tillich distingue a forma argumentativa do sentido implícito dos argumentos tradicionais a favor da existência de Deus. É preciso rejeitar a primeira, enquanto podemos aceitar o último. No fundo, já os escolásticos, apesar de formulações infelizes, "não queriam falar da 'existência', mas da realidade, da validez, da verdade da ideia de Deus, uma ideia que não trazia a conotação de algo ou alguém que poderia existir ou não"23. Para Tillich, Deus não existe, mas é o serem-si para além de essência e existência. Resulta daí que todo argumento a favor da existência de Deus seria uma negação de Deus. Falar em existência de Deus equivale a colocar o fundamento do ser dentro da totalidade dos seres. Tampouco podemos encontrar Deus na conclusão de uma argumentação lógica a partir do mundo, quando Deus é deduzido do mundo. Se derivarmos Deus a partir do mundo, ele não poderá ser aquilo que transcende infinitamente o mundo.

\footnotetext{
${ }^{22}$ Ver: J. RICHARD. La critique du supranaturalisme chez Paul Tillich. In Estudos de Religião, vol. 30, $\mathrm{n}^{\mathrm{o}}$ 3, set.-dez 2016, pp. 231-249.

${ }^{23}$ Uso a tradução brasileira revista: P.TILLICH. Teologia Sistemática. São Leopoldo, RS: Sinodal, $5^{\text {a }}$. Ed. Revista, 2005. Aqui, p. 213.
} 
Na realidade, os argumentos ou provas da existência de Deus são expressões da pergunta por Deus que está implícita na finitude humana. É que a pergunta por Deus pressupõe uma consciência de Deus.

É o caso do chamado argumento ontológico, que aponta para a estrutura ontológica da finitude. Para o ser humano, a consciência de sua finitude contém a consciência de sua infinitude potencial. "O argumento ontológico nos oferece, em suas várias formas (Agostinho, Anselmo, Descartes, Kant), uma descrição de como a infinitude potencial está presente na finitude efetiva" ${ }^{24}$. As diversas elaborações do argumento mostraram a presença de algo incondicional dentro do eu e do mundo e é este elemento que possibilita a formulação da pergunta por Deus. Deus não é uma ideia, mas uma realidade experiencial e acessível a todo ser humano. Mas não se pode usar a experiência de um elemento incondicional no encontro do ser humano com a realidade para estabelecer um ser incondicional (uma contradição em termos) dentro da realidade (como fez Anselmo, quando , a partir do seu realismo epistemológico, transformou o primum esse no ens realissimum, isto é, o princípio universal num ser universal). A verdade contida no argumento ontológico é o reconhecimento do elemento incondicional na estrutura da razão e da realidade.

Os chamados argumentos cosmológicos e teleológicos a favor da existência de Deus (Tomás de Aquino, Leibniz etc.) são a forma tradicional da questão do ser que vence o não-ser (culpa, perda de sentido, morte) e da coragem que supera a angústia. $\mathrm{O}$ argumento cosmológico no sentido restrito demonstra a existência de um ser infinito a partir da finitude do ser: a cadeia infinita de causas e efeitos ou a contingência de todas as substâncias. Na realidade, a "causa primeira" e a "substância necessária" às quais se chega são categorias da finitude hipostasiadas, "são símbolos que expressam a questão implícita no ser finito, a questão daquilo que transcende a finitude e as categorias, a questão do ser-em-si que engloba e vence o não-ser, a questão de Deus"25. Encontramos a mesma afirmação na "Dimensão perdida":

A ideia de Deus e os símbolos usados para descrevê-lo expressam a preocupação mais profunda do ser humano. Reduzidos ao único plano horizontal, fazem de Deus um ser entre outros cuja existência ou não-existência precisa ser provada. Talvez a disputa a respeito da existência de Deus - disputa na qual as duas partes estão erradas - seja o sintoma mais claro do esquecimento da dimensão da profundidade ${ }^{26}$.

E ainda na coletânea de sermões "The Shaking of Foundations": "O nome da profundidade inexaurível e do fundamento infinito de todo ser é Deus" ${ }^{27}$.

\footnotetext{
${ }^{24}$ P. TILLICH. Teologia Sistemática, p. 214.

${ }^{25}$ P. TILLICH. Teologia Sistemática, p. 217.

${ }^{26}$ P. TILLICH. La dimension oubliée. Desclée De Brouwer: Paris, 1969 (1962), p. 55.

${ }^{27}$ P. TILLICH. Les fondations sont ébranlées. Robert Morel: Paris, 1967, pp. 81-82.
} 
$\mathrm{O}$ argumento teleológico parte da estrutura significativa e compreensível da realidade, do seu telos interno, para chegar à conclusão de que as finalidades finitas implicam numa causa teleológica infinita e que os sentidos finitos e ameaçados implicam numa causa infinita e não ameaçada de sentido. De novo, esses argumentos só valem enquanto formulação da questão de um fundamento infinito, não ameaçado, de ser e de sentido.

Em todas as suas variantes, estes argumentos (cosmológicos e teleológicos) partem das características específicas do mundo para desembocar na existência de um ser supremo. Eles são válidos na medida em que proporcionam uma análise da realidade segundo a qual a questão cosmológica de Deus é inevitável. Eles não são válidos na medida em que reivindicam o fato de que a existência de um ser supremo seja a conclusão lógica de sua análise, o que, logicamente, é tão impossível quanto é, existencialmente, derivar a coragem da angústia ${ }^{28}$.

Tudo isso significa que não há uma demonstração lógica da existência de Deus, mas uma consciência ontológica e um conhecimento cosmológico do incondicional. No primeiro caso, Tillich enuncia o seguinte princípio: "Os seres humanos são imediatamente conscientes de algo incondicional que é o prius da separação e da interação entre sujeito e objeto, tanto teórica como praticamente"29. É o ser humano inteiro, em todas as suas funções, que tem consciência do incondicionado. Este não é um ser, nem o mais alto, nem mesmo Deus. Deus é incondicionado, mas o "incondicional" não é Deus. Ao termo Deus correspondem diversos símbolos concretos que expressam a nossa preocupação suprema ou o fato de sermos tocados por algo incondicional. "Mas esse 'algo' não é uma coisa, mas o poder de ser no qual todos os seres participam" ${ }^{30}$. Tentar provar a existência de Deus equivale a trata-lo como um objeto. E "o ateísmo é a resposta correta e teológica a essas tentativas"31.

Por outro lado, podemos formular do modo seguinte o princípio cosmológico: "O incondicionado que apreendemos imediatamente, sem inferências, pode ser reconhecido no universo cultural e natural" 32 . A partir da análise da finitude à luz da consciência do incondicionado, surge um novo modo de percepção cosmológico, por meio de conceitos como contingência, insegurança, transitoriedade e seus correlatos psicológicos: angústia, preocupação e falta de sentido. Podemos também perceber o elemento incondicional na criatividade da natureza e da cultura. Em particular, torna-se possível uma interpretação religiosa da cultura, pois cada criação cultural

\footnotetext{
${ }^{28}$ P. TILLICH. Teologia sistemática, p. 216.

${ }^{29}$ P. TILLICH. Dois tipos de filosofia da religião, In Teologia da cultura. Fonte Editorial: São Paulo, 2009 (1946), p. 60.

${ }^{30}$ P. TILLICH. Dois tipos de filosofia..., p. 62.

${ }^{31}$ P. TILLICH. Dois tipos de filosofia..., p. 62.

${ }^{32}$ P. TILLICH. Dois tipos de filosofia..., p. 64.
} 
é expressão da preocupação suprema ou do fato de ser tocado pelo incondicionado, pela sua irrupção no condicionado.

O conhecimento do Deus que é, ao mesmo tempo, fundamento do ser e de todos os entes, e o "totalmente outro" ou o "extaticamente transcendente", é analógico ou simbólico, e não objetivo. Embora use o material da experiência cotidiana para falar de Deus, todo símbolo religioso se nega a si mesmo em seu sentido literal, mas se afirma em seu sentido autotranscendente. Isto é, todo símbolo religioso é paradoxal, pois contém, ao mesmo tempo, um elemento de propriedade e um elemento de inadequação. O símbolo representa o poder e sentido daquilo que simboliza através de sua participação nele. Tudo o que a religião afirma sobre Deus, inclusive suas qualidades, ações e manifestações, tem um caráter simbólico ${ }^{33}$.

No artigo Dois tipos de filosofia da religião (1946), já citado, Tillich estende o mesmo raciocínio ao argumento moral de Kant:

Afirma-se frequentemente que o tipo moral de filosofia da religião (a partir do assim chamado argumento moral de Kant em favor da existência de Deus) representa uma novidade. Mas não é bem assim. O argumento moral pode ser interpretado tanto cosmológico quanto ontologicamente. No primeiro caso, seria fundamento de uma inferência chegando ao ser superior para garantir a unidade suprema de valor e perfeição, ou a crença no poder vitorioso do processo criador de valores. No segundo caso, a experiência do caráter incondicional do mandamento moral é, imediatamente, sem qualquer inferência, a percepção do absoluto, embora não do ser supremo ${ }^{34}$.

\subsection{O curso de Harvard sobre Filosofia da religião ${ }^{35}$}

No curso de filosofia da religião de Harvard (1962), Tillich faz uma exposição mais pormenorizada dos argumentos. No caso do argumento ontológico, ele distingue entre uma forma externa e uma forma interna. $\mathrm{O}$ argumento ontológico externo é o platônico: só podemos ter uma medida do bom, do verdadeiro, do belo porque o nosso espírito (nous) participa do bom em si, do belo em si, do verdadeiro em si. Trata-se da ideia ou visão (eidos) (não da boa ideia!), da imagem essencial que nos permite reconhecer uma árvore ou um ser humano quando os encontramos. A ideia é algo bem real, é o poder de ser de uma coisa. Então, deve haver uma ideia ou essência do bem que é a mais alta de todas, que inclui todas as outras essências e que é o critério para bom e o mau. Aqui, Platão comete o famoso salto, ao chamar

\footnotetext{
${ }^{33}$ Cf. P. TILLICH. Teologia sistemática, pp. 304-305.

${ }^{34}$ P. TILLICH. Dois tipos de filosofia da religião, pp. 57-58.

${ }^{35}$ Curso inédito oferecido em Harvard em 1962. O texto me foi gentilmente cedido por Jean Richard, por intermédio do meu aluno Thiago Rafael Englert Kelm.
} 
esta natureza essencial de "Deus". Na realidade, ele usa de cautela, ao não dizer simplesmente que há um ser existente que é bom. Platão diz: eis a fonte de toda bondade, a ideia, a essência do bem, e ele não vai além disso. Ele chama essa ideia "o divino" ou "Deus", mas não é um ser, Platão usa o mesmo raciocínio a respeito do belo e do verdadeiro. Tudo isso leva até a esfera do último, até o problema, a questão de Deus, mas não leva à existência de um Deus ou de vários seres chamados deuses $^{36}$.

$\mathrm{O}$ argumento ontológico interno é a forma anselmiana ou agostinhana. O argumento já foi refutado muitas vezes (Duns Scotus, Hume, Kant etc.), mas a refutação não alcança realmente o sentido do argumento, o sentido que Tillich chama "descrição": a face descritiva de todos os argumentos é verdadeira, justificada. A face argumentativa, conclusiva, o salto para a existência de um ser supremo é falsa, porque o Ultimo não "existe". O que existe, existe nas condições da existência, o que significa tempo e espaço, existere, "ir da potencialidade à atualidade", mas Deus, conforme a intenção religiosa, está além disso. A descrição do argumento ontológico interno é verdadeira: olhamos para dentro de nós e descobrimos nas profundidades do nosso próprio ser a presença, a consciência de algo de infinito apesar da nossa finitude. "Descobrimos o que chamei - numa outra aula- o princípio da coincidência do finito e do infinito." Não é um ser, pois não seria incondicionado, mas muito condicionado. Mas há consciência do princípio do infinito, do incondicionado, do absoluto, independentemente do modo como queiramos nomeá-lo. Está presente em termos de uma preocupação incondicional, do caráter incondicional do verdadeiro e do imperativo moral. Toda tentativa de estabelecer a existência de Deus o torna menos que Deus, lhe atribui o papel de um ser finito ao lado de outros seres finitos.

Há outra forma do argumento ontológico, desenvolvida por Agostinho na sua discussão com quem duvida. Ele aparece do seguinte modo: "Você está duvidando; isto significa que você está procurando a verdade, que você aceita a ideia de verdade, mas você não sabe como alcança-la. Ao duvidar, você afirma a ideia de verdade que está agindo em você". Até aí, está certo. Não o salto que Agostinho faz em forma de oração: "E essa verdade es tu, meu Deus". O que é verdadeiro é que onde há um ser humano (um ser que não está completamente submetido ao reino temporal das coisas), o estado de estar guiado pela busca da verdade, pelo reconhecimento da verdade, apresenta algo de incondicional, embora toda expressão humana do incondicional seja condicionada. E a consciência de algo incondicional em todas as condições da existência é universalmente humana. Mas não leva a um ser existente chamado Deus ${ }^{37}$.

\footnotetext{
${ }^{36}$ Cf. Lecture 5. Cassette 3-4, p. 79.

${ }^{37}$ Cf. P. TILLICH. Lecture 5. Cassette 3-4, pp. 9-11. No curso sobre Ontologie, oferecido em Berlim em 1951, Tillich lembra que, se o elemento incondicionado não estivesse presente dentro do condicionamento do Self e do mundo, a questão de Deus não poderia nunca ter sido colocada, seria
} 
Tillich distingue uma forma negativa e uma forma positiva do argumento cosmológico: Os argumentos cosmológicos partem da experiência do mundo. Olhando para a realidade que encontramos, achamos fatos nela, que podemos chamar "estigmas" (como as chagas de São Francisco de Assis). Toda coisa no mundo apresenta o estigma, a marca da finitude. A partir daí, desenvolve-se os argumentos cosmológicos negativos. Uma primeira forma é a passagem da experiência da contingência, da não necessidade de cada coisa e da própria existência à afirmação de algo absolutamente necessário. E esse "algo necessário" é identificado com o Divino. Uma segunda forma admite que toda realidade pressupõe uma causa, a qual pressupõe também uma causa e assim por diante, numa infinita corrente de causas. Daí o argumento: deve haver uma causa primeira no início do encadeamento das causas finitas. Aí vem a terceira forma: para que possa existir uma realidade condicionada, devemos pressupor algo incondicional, que chamamos o Divino. Em termos de conclusão (do contingente ao necessário, da corrente das causas à causa primeira, do condicionado ao incondicionado) o argumento não pode nunca levar até um ser divino porque, se a causa é causa, a nossa mente não pode parar de perguntar pela sua causa. Temos as famosas palavras de Kant criticando os argumentos cosmológicos: "Tal ser supremo chamado Deus, que é a primeira causa, perguntaria a si mesmo: e de onde sou eu? [...] Neste momento, tudo desaparece para nós e estamos num vácuo que é pior que as piores imaginações de um poeta desse tempo". Seria a falência da própria razão crítica. Isso significa que, por esse caminho, nunca chegaremos até um assim chamado Ser supremo ${ }^{38}$.

$\mathrm{O}$ argumento teleológico é chamado de argumento cosmológico positivo: É geralmente chamado de argumento do desígnio ou de argumento teleológico. A palavra grega Telos designa o fim interno, a causa que governa a minha vida, que ele possa ou não ser alcançado. É o que Aristóteles chamava entelechia. A finalidade interna está presente em todo elemento vital e também nas estruturas que mantém o universo unido. De novo, não se justifica dar o salto do desígnio ao criador do desígnio. O que se pode fazer, como Heráclito e os estoicos, é descrever o universo como algo determinado pelo logos ou determinado pela sabedoria em toda a sua estrutura. Só podemos descrever o caráter ou sentido teleológico da totalidade do real. Mas há também uma dis-teleologia, o oposto da finalidade interna. São as formas destrutivas. Como disse Heráclito, não há apenas o logos, mas também a

uma pergunta sem sentido, e nenhuma resposta poderia ter sido dada. Não haveria nenhum ser humano para receber a revelação. Assim se exprime Agostinho: "Não poderia ter perguntado a teu respeito se não já soubesse algo de ti". Não se pode perguntar a respeito de algo do qual não se participa de modo algum. Ver: P. TILLICH. Ontologie (Freie Universität Berlin, Sommersemester 1951). In Berliner Vorlesungen III (1951-1958). Ergänzungs- und Nachlässbände zu den Gesammelten Werken XVI. De Gruyter: Berlin/New York, 2009, pp. 1-168. Tillich trata dos argumentos na lições 15 e 16: Vorlesung 15: Ontologie und Religion, p. 148-157; Vorlesung 16: Ontologie und Religion (Fortsetzung), pp. 158168.

${ }^{38}$ Cf. P. TILLICH. Lecture 5. Cassette 3-4, pp. 16-21. 
moria, a loucura do real. Faz parte da descrição da realidade o conflito permanente entre uma estrutura fundamentalmente sensata e a contradição da falta de sentido nela em cada momento ${ }^{39}$.

Kant mostrou que em todos os argumentos cosmológicos, há um elemento ontológico, isto é, o pressuposto que colocamos a questão do finito, que não estamos satisfeitos e não podemos nos identificar com a nossa finitude, que a transcendemos. Em todas as nossas experiências da finitude há um elemento que nos leva além da simples aceitação, a formular a questão sempre posta em todo o gênero humano. Essa questão pressupõe a presença da experiência do que não é simplesmente causado ou condicionado ou finito. É neste ponto do argumento cosmológico que está implicado um elemento ontológico: porque alguém que é consciente da sua finitude pode sentir essa finitude como algo que o leva a uma pergunta, se ele não está consciente de algum modo do infinito que se opõe a ele? ${ }^{40}$

A defesa de Kant a favor do argumento moral cai perante a própria crítica aos outros argumentos. O que é verdadeiro no argumento de Kant - assim como nos outros argumentos - é a experiência do caráter incondicional do imperativo moral. Mas Kant tira conclusões além dessa experiência, quando parte da ideia que, já que em nosso tempo de vida, o elemento moral e a felicidade não coincidem, deve haver uma realização da unidade de ambos, uma realização do nosso ser pela obediência ao imperativo moral, e o garante, o fiador (não a garantia) desta unidade é Deus. Deus é assim deduzido enquanto postulado ou exigência lógica. Mas não há como provar isso efetivamente ${ }^{41}$. Deus garante que aquele que vive conforme ao imperativo moral alcançará a felicidade, talvez não nessa vida, mas numa outra vida, e garante também, desse modo, a imortalidade da alma.

No mesmo curso de Harvard, Tillich fala nas provas da existência de Deus no contexto da discussão sobre os métodos da filosofia da religião. O método mais antigo, já presente na Grécia clássica e atravessando a história do pensamento

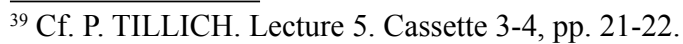

${ }^{40}$ Cf. P. TILLICH. Lecture 5. Cassette 3-4, p. 25.

${ }^{41}$ Cf. P. TILLICH. Cassette 5-1, pp. 5-7. No curso sobre Ontologia, Tillich reafirma que, quando Agostinho e Kant não argumentam nem provam, mas apenas mostram, eles não podem ser refutados. Pois não se pode fazer nada além de mostrar, na análise da existência. Eles mostram que, em cada encontro com a realidade, um elemento incondicionado está presente. Mas Agostinho e Kant vão mais longe: eles deduzem da análise um conceito de Deus que é mais que o ser em si, que o bom em si, que o verdadeiro em si. Eles passam da dimensão analítica para uma dimensão construtiva, e aí começam os problemas. Agostinho identifica o verdadeiro em si com o Deus da Igreja, e Kant procura deduzir, a partir do imperativo categórico, alguém que garanta a unidade da moralidade e da felicidade. Nos dois casos, o ponto de partido é correto e a conclusão falsa. Pois é contraditório e impossível derivar um ser infinito e incondicionado presente no mundo a partir da experiência de um elemento incondicionado no encontro do ser humano com a realidade
} 
até o século XX, é o método ontológico da finitude. A sua motivação é a questão do estatuto ontológico dos deuses. A questão é sempre: o que dizer de Deus, dos deuses? São coisas, objetos, seres humanos? Eles possuem realidade ou são produtos da imaginação? Essas questões partem de um pressuposto: de que a validade da religião, de seus atos de devoção e obediência, depende da existência de seres que são chamados deuses ou Deus, dentro ou fora do Cosmos. Então, a filosofia da religião procurou fundamentar racionalmente o dado da fé, para ajudar aqueles que duvidam da existência de Deus. Assim, ela elaborou o argumento a favor da existência de Deus. Outra forma de filosofia da religião tentou argumentar a favor da sua inexistência. Ora, ambas as tarefas são impossíveis, pois a primeira coisa que precisamos dizer a respeito de Deus, é que Deus não existe em nenhum dos sentidos possíveis da palavra "existência". Ele está além da essência e da existência. Então, as provas a favor da existência de um ser chamado Deus levam a tudo, salvo até Deus. Contudo, esses argumentos devem ser discutidos, mas não como provas da existência de um ser ao lado de outros seres. Eles possuem um valor infinito - e, por isso, resistem até hoje - por outro motivo: sua validade reside na descrição, negativa ou positiva, da situação humana, que eles fornecem, na descrição da finitude do ser humano e do seu mundo e, ao mesmo tempo, na descrição da participação do Infinito no finito e vice-versa. O que não se justifica é o salto que eles fazem, da análise da finitude da existência para um ser chamado Deus.

Tillich pergunta, no final, porque há um grupo entre os maiores filósofos de todos os tempos que se deixa convencer pelos argumentos e há um grupo de outros filósofos tão importantes que os rejeita. Deve haver para isso um motivo mais profundo. Tillich chega de novo à resposta de que a descrição da realidade encontrada como contingente e condicionada numa corrente de causas e efeitos é um elemento existencial em toda a filosofia do passado. É o que os existencialistas (e Tillich remete à experiência do ser-jogado, de Heidegger) chamam hoje, com uma só palavra, descrição da finitude. Os argumentos formulados no passado antecipam o que o existencialismo moderno formulou numa terminologia mais psicológica. Em suma, na análise da finitude, há sempre uma experiência do contrário. Para poder dizer de algo que é finito, precisamos ter em nós a consciência do infinito que o finito não é e do qual está excluído. Desde a mais antiga mitologia, uma questão foi sempre colocada: O que significa o fato da finitude? Há sempre uma consciência do oposto, do infinito, do incondicional, da causa primeira, do absoluto, do necessário. Nós humanos fazemos essa experiência com todo o nosso ser: descobrimos o elemento do finito e descobrimos o elemento do infinito que se opõe ao finito e do qual o finito está excluído. A questão do infinito não pode levar ao estabelecimento de um ser infinito. A religião é a experiência extática na qual a questão do infinito encontra resposta numa linguagem simbólica. Mas essa experiência não pode ser substituída por um argumento, porque os argumentos se movem sempre dentro da realidade finita e só podem levar até seres finitos ${ }^{42}$.

${ }^{42}$ P. TILLICH. Lecture 5, cassette 3-4, p. 1-5. 


\section{Considerações finais: a fé da razão}

Tillich compartilha com Kant a consciência imediata do Incondicionado, seja na forma do imperativo moral ou do Ultimate Concern que transparece através de todas as formas culturais. Em Kant como em Tillich, a experiência da presença do incondicionado na consciência substitui os argumentos para a existência de Deus. Em Kant, essa substituição é apenas parcial, pois, a partir daí, ele tenta estabelecer um novo argumento a favor da existência de Deus. Em relação a Kant, Tillich coloca a religião no sentido amplo no lugar da moral. É a religião enquanto manifestação do Incondicionado que dá sentido à moralidade e à cultura. Podemos dizer que nos dois casos, o incondicionado é objeto de uma intuição originária que se expressa num conceito místico-transcendental puramente formal.

O pensamento moderno opera uma estrita separação entre a fé e a razão. Elas são válidas, cada uma na sua ordem, com a condição de não querer interferir no domínio da outra. É a posição de Kant, que reserva, todavia, uma zona fronteiriça, na qual a filosofia pode ainda aprender muito da fé, tendo, contudo, a última palavra a respeito dos principais problemas que preocupam o ser humano. Falamos a respeito de Kant de uma fé da razão. De fato, haveria, no pensamento de Kant, ainda lugar ainda para certa fé, não uma fé estatutária, feita de crenças, de ritos e de instituições, mas uma fé originária da razão, condição de possibilidade de todo sentido, religioso ou não.

Por sua vez, Tillich fala num "êxtase da razão". Para Tillich, a fé é preocupação suprema, primeira e última, é o fato de ser possuído pelo Incondicionado, antes e além de toda preocupação concreta e de toda nomeação do Incondicionado. Em outras palavras, a fé diz respeito a um originário, anterior ao sentido e à própria linguagem, fonte última e abismo do sentido. A fé é o direcionamento para o Incondicionado. "A fé aponta para uma dimensão ontológica que está além da capacidade humana de explicação pelo entendimento ${ }^{43}$. Mas a razão é condição de possibilidade da fé: a fé é o ato pelo qual a razão esforça-se por alcançar, de modo extático, um além de si mesma ${ }^{44}$. Consciente de sua finitude, a razão a supera. Ela é empurrada para além de si mesma, sem deixar de ser razão e razão finita. $O$ êxtase é a realização e não a destruição da razão. A fé é a razão em êxtase ${ }^{45}$. Ela é transcendência imanente ou abertura do mundo à exterioridade.

A fé absoluta, ou o estado de ser possuído pelo Deus além de Deus (God beyond God) [...] é sempre um movimento presente em, com e subjacente aos outros estados do

\footnotetext{
${ }^{43}$ E. GROSS. O conceito de fé em Paul Tillich, In Correlatio, vol. 12, no 23, junho de 2013, p. 10.

${ }^{44}$ P. TILLICH. Dynamique de la foi. Casterman: Paris - Tournai, 1968, p. 90.

${ }^{45}$ P. TILLICH. Dynamique de la foi, p. 91.
} 
espírito. É uma situação na fronteira das possibilidades humanas. Ela é essa fronteira. [...] Ela é sem nome, sem igreja, sem culto e sem teologia. Mesmo assim, é ela que opera na profundidade de todas estas realidades. Ela é o poder do ser, do qual cada uma destas realidades participa e do qual elas são expressões fragmentárias ${ }^{46}$.

Para Tillich, o equívoco mais frequente consiste em considerar a fé como ato de conhecimento comportando um fraco grau de certeza. Ao contrário, a fé é participação ao que nos importa de modo absoluto, participação com o nosso ser inteiro. A certeza da fé não se baseia em nenhuma evidência perceptiva ou teórica. Ela é "existencial", o que significa que a totalidade da existência - e, singularmente, a práxis - está envolvida nela. É uma questão de "ser ou não ser"47.

Numa outra ocasião, mostrei como o pensamento de Kant encontra prolongamentos na reflexão filosófica sobre a religião de dois autores chamados pós-modernos: Jacques Derrida e Jean-Luc Nancy. Para Jacques Derrida, trata-se de encontrar a condição de possibilidade abstrata, a origem comum da fé e do saber (ou razão). O seu lugar comum identifica-se com a estrutura a priori (axioma) da experiência - anterior ao a priori religioso de um possível homo religiosus -, ou com uma revelabilidade pressuposta por toda revelação religiosa ou racional, ou ainda com o vínculo social originário anterior a todo vínculo social concreto. Neste lugar dos limites da simples razão, fé e razão identificam-se de certo modo, enquanto fontes da religião, enraizadas na mesma condição de possibilidade, na mesma luz originária ou no mesmo deserto no deserto. A fé que habita qualquer ato de linguagem e qualquer mensagem dirigida ao outro é um evento performativo axiomático (quase transcendental) ou místico exterior e anterior à realidade fundada ${ }^{48}$.

Retomando a abordagem de Kant, Jean-Luc Nancy parece evitar o lugar da fronteira ou dos confins da religião histórica e da religião racional, optando decididamente por uma fé sem religião, uma fé que seja desprovida de crenças, de ritos e de instituições. O pensamento está diante da tarefa de abrir a racionalidade à dimensão própria do absoluto, de dar lugar - conforme as palavras de Kant - a uma fé da razão. Kant escreveu: "Tive que suprimir o saber para dar lugar à fé". Não há outro preenchimento de sentido além da própria visada ou intencionalidade da fé. Ela é atestação de uma ausência de presença e semelhança. Seu verdadeiro correlato não é um objeto, mas a palavra de Deus ou a palavra do outro. Distinta de qualquer crença, a fé é por si mesma, fidelidade, confiança e abertura da possibilidade em que ela confia. Nessa condição, é sempre adesão ao infinito de sentido.

\footnotetext{
${ }^{46}$ P. TILLICH. The Courage to Be. Yale University Press: New York, 1952, p. 229.

${ }^{47}$ P. TILLICH. Dynamique de la foi, pp. 47-51.

${ }^{48}$ Cf. J. DERRIDA. Foi et savoir. Les deux sources de la "religion" aux limites de la simple raison, In J. DERRIDA \& G. VATTIMO (dir.). La religion. Seuil: Paris, 1996, pp. 9-86.
} 
A fé é o ato da razão que se refere, por si mesma, ao que a transpassa e ultrapassa infinitamente. Pois a própria razão exige incondicionalmente uma abertura e uma elevação acima de si mesma. A fé é o local de nascimento, o evento criador de "algo", "alguém" ou o "nada" ao qual ela remete. Deus aparece, assim, como fruto da fé, a qual, ao mesmo tempo, depende totalmente da sua graça. Só podemos aceder à palavra (à linguagem) e ao sentido graças à fé, isto é, uma confiança prévia no sentido ao qual o outro nos convida. Nancy remete aqui a Derrida, quando este fala “do que na fé diz 'sim' antes ou além da questão, na experiência já comum de uma língua e de um 'nós"’49.

Tanto em Derrida quanto em Nancy, há fé, confiança, crédito na possibilidade originária como estrutura geral da experiência, condição de possibilidade da linguagem e do sentido. Há confiança prévia no sentido originário e na alteridade absoluta, como a priori, quase transcendental.

Não posso deixar de ressaltar, ao terminar, a dependência de todos esses autores em relação ao cristianismo, enquanto fundo indestrutível da cultura ocidental. No caso de Kant e Tillich, trata-se de um cristianismo bem protestante. Tillich reconhece que a teologia protestante só pode aceitar a teologia natural - que produziu os argumentos a favor da existência de Deus - dentro dos limites que ele colocou na sua reinterpretação dos argumentos. Ele não quer adotar uma posição protestante radical, como a de Barth, que rejeita taxativamente qualquer tipo de teologia natural, mas se recusa também a voltar aquém de Kant, cujo pensamento constitui para ele um divisor de águas.

\footnotetext{
${ }^{49}$ Cfr. J-L. NANCY, La déclosion (Déconstruction du christianisme I). Paris : Galilée, 2005. Aqui, p. 91.
} 